\title{
Ueber einen seltenen Fall von Echinococcus der Gebärmutter und der Eierstöcke.
}

\author{
Von
}

Dr. Tittel in Zittau.

Im Jahre 1884 schrieb Fritsch in seinem Buch über Krankheit der Frauen: "Nur wenig sichere Fälle von Echinococcus des Uterus existiren." Der Zufall wollte es, dass ich wenige Jahre später Gelegenheit hatte, einen ganz eclatanten Fall von Echinococcus der Gebärmutter und der Eierstöcke zu beobachten, desseu Veröffentlichung damals, ich weiss nicht mehr aus welchen Gründen, unterblieben ist. Um so mehr freue ich mich, diesen gewiss seltenen Fall noch nachträglich hier an dieser Stelle veröffentlichen zu können. Kommen doch nach einer früheren Zusammenstellung aller bekannt gewordenen Fälle von Echinokokken nur etwa 4 pCt auf die Genitalien und das kleine Becken.

Im April 1888 ersuchte mich Dr. 0. in Hirschfelde die Frau des Garten- und Feldbesitzers A. in Dittelsdorf, die er schon lange wegen eines Herzklappenfehlers in Behandlung habe und bei der er neuerdings ein schweres Unterleibsleiden vermuthe, zu untersuchen. Wir besuchten hierauf die Kranke zusammen in ihrer Behausung und jeh erfuhr anamnestisch zunächst Folgendes:

Die circa 40 jährige Frau hatte schon seit 3-4 Jahren eine allmähliche Zunahme des Unterleibes bemerkt, zu der sich seit mehreren Monaten eine immer mehr zunehmende Schwellung der Beine und der äusseren Geschlechtstheile gesellt hatte, so dass sie schon seit Wochen nicht mebr im Stande war sich fortzubewegen. Der Appetit hatte vollständig aufgehört, der Stuhlgang war retardirt und die Urinabsonderung sehr spärlich geworden. Die Periode war immer regelmässig, wenn auch sehr spärlich eingetreten. Entbindungen hatten in den letzten 
10 Jahren nicht mebr stattgefunden. Abgesehen von wiederholt auftretenden Anfällen von Herzklopfen und Athemnoth, klagte die Kranke hauptsächlich über eine zunehmende Schwäche, über eine unerträgliche Spannung im Unterleib und eine bleierne Schwere in den Beinen.

Die Untersuchung ergab nun folgenden Befund: Die Kranke ist eine kräftig gebaute Frau, deren Oberkörper aber stark abgezehrt ist. Die Lungen sind gesund. An der Herzspitze hört man ein lautes systolisches Geräusch und es ist eine mässige Vergrösserung des Herzens zu constatiren. Der Puls ist schwach, etwas frequent, aber regelmässig. Die Athmung ist beschleunigt. Der Unterleib ist sehr stark ausgedehnt und hochgradig gespannt. In Folge eines àusgedehnten Oedems der Bauchdecken ist es indess sebr schwer ihn genau abzutasten. Man fühlt nur mit Mühe einen grossen prall elastischen Tumor, der etwa handbreit über den Nabel hinaufragt; daneben scheint ein mässiger Ascites vorhanden zu sein. Ob der Tumor der Gebärmutter oder den Eierstöcken angehört, lässt sich nicht feststellen, zumal eine innere Untersuchung infolge hochgradigen 0edems der änsseren Genitalien, die noch dazu sehr empfindlich sind, gar nicht auszuführen ist. Die Beine sind ebenfalls hochgradig ödematös. Der Urin ist sehr spärlich, enthält kein Eiweiss.

Da ich unter diesen Umständen eine Probepunktion nicht riskiren wollte und mir auch gar Nichts von einer solehen versprach, so konute ich eine bestimmte Diagnose nicht stellen. Es handelt sich jetzt nur darum, ob der Zustand der Fran einen schweren operativen Eingriff zulassen würde. Da die Kranke einen zur Zeit leidlich compensirten Herzfehler hatte, so kounte ich annehmen, dass die hochgradigen Oedeme nicht durch diesen allein herbeigeführt seien, sondern wohl in der Hauptsache durch einen grossen, eventuell malignen, den ganzen Unterleib ausfüllenden Tumor entstanden waren. Da die Kranke ausserdem in Folge ihres unerträglichen Zustandes auf Vornahme einer Operation bestand, so entschloss ich mich, nachdem ich sie noch 2 oder 3 Mal untersucht hatte, aber zu keinem anderen Resultate gekommen war, dieselbe auszuführen.

Ich liess die Kranke in das Stadtkrankenhaus nach Zittau überführen, woselbst ich unter freundlicher Assistenz des damaligen Assistenten des Prof. Säxinger in Tübingen, jetzigen Dr. B. in Ulm, der zufällig in Zittau zu Besuch weilte, die Operation vornahm. Glücklicher Weise vertrug die Kranke die Chloroformnarkose sehr gut, so dass von dieser Seite während der Operation keine Störungen eintraten.

Nach Eröffnung der Bauchhöble durch einen ziemlich langen, handbreit über den Nabel hinaufreichenden Schnitt und Entleerung von ea. 2 Liter freier Bauchhöhlenflüssigkeit, präsentirte sich der erwartete Tumor - ich muss sagen zu meiner Bestürzung - als die stark vergrösserte Gebärmutter, etwa dem 7. bis 8 . Schwangerschaftsmonat entsprechend, während ich doch eine Schwangerschaft vollständig ausschliessen zu müssen geglaubt hatte. Den Eindruck eines myomatösen Uterus gewann ich auch nicht, denn die Gebärmutter fühlte sich überall ganz gleichmässig prall elastisch an und zeigte nirgends eine auffallende Prominenz. Als ich nun nach den Eierstöcken fühlte, zeigten sich beide stark vergrössert, annähernd kindskopfgross. Ohne besondere Mühe entfernte ich bierauf den rechten Eierstock, der an einem $4-5 \mathrm{~cm}$ breiten Stiel sass. Ich glaubte ein papilläres Kystom vor mir zu haben und war deshalb im höchsten Grade überrascht, als ich die Geschwulst 
mit einer grossen Menge von Echinococcusblasen gefüllt fand. Der linke Eierstock wurde nun ebenfalls obne besondere Mähe entfernt und bot ganz dasselbe Bild. Ueber die Beschaffenheit der Gebärmutter war nun hiernach kaum ein Zweifel mehr. In der Voraussetzung, dass sie ebenfalls mit Echinokokken gefüllt sein müsse, eröffnete ich sie mit einem 10-12 cm langen Schnitt in der Längsrichtung, ganz wie beim Kaiserschnitt. In der That war die Gebärmutterhöhle mit einer Unmenge von Echinococcusblasen gefüllt, die ich mit der Hand entfernte; sie waren so reichlich vorhanden, dass ein grosses Waschbecken mit denselben beinahe angefüllt wurde. Wenn ich gehofft hatte, nunmehr die Gebärmutter wieder zunähen zu können, zumal keine wesentliche Blutung vorhanden war und die Gebärmutter sich ganz leidlich contrabirte, so fand ich jedoch bei genauem Zusehen, dass bereits die Gebärmutterwand in grosser Ausdehnung von Blasen durchsetzt war. Es blieb darum nichts übrig als die totale Entfernung der Gebärmutter, sollte die Operation einen dauernden Erfolg haben. Ich entschloss mich, da der Mutterhals gesund erschien, zur Amputatio supravaginalis, die ich in der Hauptsache nach der Martin'schen Methode mit Verwendung eines Gummischlauches, durch den ich das Collum uteri festlegte, ausführte. Der Blutverlust war hierbei verbältnissmässig gering. Am meisten störte mich während der Operation das Vorfallen der Därme - Beckenbochlagerung war damals leider noch nicht bekannt - die in grosser Ausdehnung aus der Bauchhöhle hervortraten und durch grosse warme Compressen mühsam zurückgehalten werden mussten. Diesem letzteren Vorgang während der beinahe 3 Stunden dauernden Operation gebe ich die Hauptschuld an íhrem letalen Ausgang. Während nämlich die ersten Tage nach der Operation ganz leidlich ohne Fieber und ohne wesentliche Schmerzen verliefen, wollte das Erbrechen, welches ich anfangs als Chloroformnachwirkung ansah, gar nicht nachlassen und vom fünften Tage ab waren dem Erbrochenen deutliche Kotbmengen beigemischt. Dass irgend eine Einklemmung des Darmes stattgefunden habe, erschien mir nicht wahrscheinlich, weil der Leib auch jetzt gar nicht aufgetrieben war. Trotzdem hätte ich den Leib jetzt nochmals geöffnet, aber die Angehörigen verweigerten jeden weiteren Eingriff, zumal der Zustand der Kranken sich von Stunde zu Stunde verschlechterte und das Kothbrechen immer heftiger wurde. In der Nacht vom ๖. zum 6. Tag trat der Exitus letalis ein. Leider wurde die Leiche gleich am zeitigen Morgen nach der Heimath der Verstorbenen abgeholt, so dass eine Oeffnung der Leiche unterbleiben musste und somit eine Feststellung der Todesursache nicht möglich war.

Ich vermuthe, dass es sich um eine Darmlähmung gehandelt hat in Folge des langen Freiliegens und der Abkühlung der Därme, eine Vermuthung, in der ich durch Prof. Olshausen, mit dem ich kurze Zeit später einmal über den Fall zu sprechen Gelegenheit hatte und der schon ähnliche Fälle beobachtet hatte, noch bestärkt wurde. Durch Beckenhochlagerung, die wie gesagt damals noch nicht bekannt war, wäre hier vielleicht der letale Ausgang vermieden worden. 
Tittel, Ueber einen seltenen Fall von Echinococcus der Gebärmutter. 183

Zum Schluss muss ich betreffs der Aetiologie noch nachholen, dass die Kranke, die in der Landwirtschaft aufgewachsen war, mir auf Befragen angab, dass sie von Jugend auf sehr viel mit Hunden zusammen gekommen sei und ebenso, dass sie sowohl früher bei ihren Eltern, als auch nach ihrer Verheirathung sehr viel das Melken besorgt habe.

Ob aus der Gegend, aus der die Kranke stammte, etwa sonstige Fälle von Echinococcus beobachtet worden sind, bahe ich nicht in Erfahrung bringen können. 